\title{
Ironless In-Wheel Hub Motor Design by Using Multi-Domain Finite Element Analyses
}

\author{
Oliver Winter*, Stephan Ucsnik ${ }^{\S}$, Michael Rudolph*, Christian Kral*, Erich Schmidt ${ }^{\ddagger}$, \\ AIT Austrian Institute of Technology, Mobility Department, \\ ${ }^{*}$ Electric Drive Technologies, ${ }^{\S}$ Light Metal Technologies, 1210 Vienna, Austria, Email: oliver.winter@ait.ac.at \\ $\ddagger$ Vienna University of Technology, Institute of Energy Systems and Electrical Drives, 1040 Vienna, Austria
}

\begin{abstract}
In this paper, a lightweight ironless axial flux permanent magnet drive concept is presented. The in-wheel hub motor has a high torque to weight ratio and achieves a high efficiency, which extends the operation range of battery powered vehicles. The steps from preliminary design to manufacturing of the components are described. The paper includes Finite Element Analyses in different physical domains.
\end{abstract}

\section{NOMENCLATURE}

$\begin{array}{ll}\text { CFD } & \text { Computational fluid dynamics. } \\ \text { CFRP } & \text { Carbon fibre reinforced plastic. } \\ \text { EM } & \text { Electromagnetic calculation. } \\ \text { FEA } & \text { Finite element analysis. } \\ \text { FVA } & \text { Finite volume analysis. } \\ \text { GRP } & \text { Glass fibre reinforced plastic. } \\ \text { ICE } & \text { Internal combustion engine. }\end{array}$

\section{INTRODUCTION}

A mayor drawback of electric vehicles is nowadays their limited operation range. Consequently, various drive train concepts like many types of hybrid and near wheel electrical motors have been developed. Although various concept cars and even standard models were presented on the market, their limited range in comparison to ICE powered vehicles is still an unresolved problem. Mainly because of weight limitations, the energy-storage capacity of a battery is significantly smaller than that of a fuel tank. In-wheel hub motors improve this situation because they minimize the vehicle mass. The added unsprung mass does not impair driving comfort or safety [1], [2]. Among all types of electric machines, axial flux machines provide the highest torque to volume ratio if the radial diameter is not strictly limited [3], [4]. The most efficient, light weighted topology is the air cored axial flux machine equipped with magnets in Halbach arrangement [5], [6]. If both minimum mass and high efficiency are desired, this topology is preferred and it is therefore used in the proposed design.

The effect of flux concentration due to changing magnetization patterns in magnetic materials was discovered in 1973 [7]. Later, it was named after K. Halbach who worked on undulators for the production of synchrotron radiation [8]. Applied to rotating electric machines, Halbach magnet arrays produce higher torque as magnetically-backed rotors [9]. A 2D representation of a double sided Halbach magnet array is shown in Fig. 1.

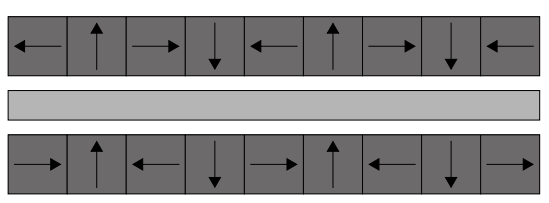

Halbach magnet array

Airgap winding

Halbach Magnet array

(i)
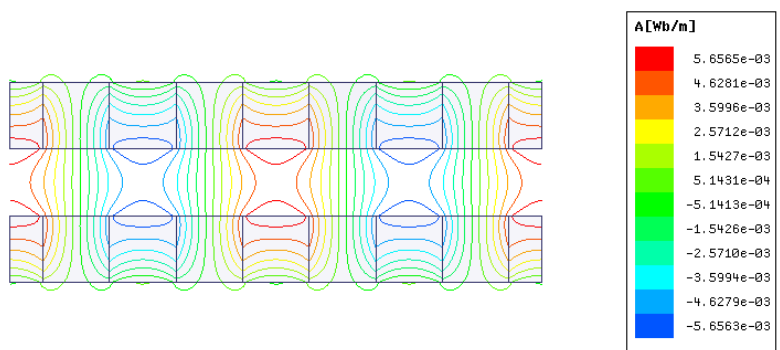

(ii)

Fig. 1. Double sided Halbach magnet array arrangement without back iron, (i) magnetization pattern, (ii) resulting field pattern

\section{SPECIFICATION AND PROJECT WORKFLOW}

The main objective of most in-wheel concepts (e.g. Michelin "active wheel", Siemens VDO/Continental "ecorner", Volvo Protean "ReCharge", Mitsubishi "MiEV") is the direct substitution of the ICE and the gearbox. Such in-wheel concepts are used for vehicles from A-class up to transporters. The continuous power output for the given examples ranges from 20 to $64 \mathrm{~kW}$ per wheel. Assuming a nominal efficiency of $\eta=92 \%$, the nominal thermal losses of each electric machine are in the range from $1.6 \mathrm{~kW}$ to $5.12 \mathrm{~kW}$. Due to limited space inside a standard rim, it is assumed that the heat transfer surface to the cooling medium (mostly liquid cooled)

TABLE I

VIRTUAL VEHICLE SPECIFICATION

\begin{tabular}{|l|c|c|}
\hline Description & Symbol & Nominal value \\
\hline \hline Vehicle mass & $m_{v v}$ & $250 \mathrm{~kg}$ \\
\hline Frontal area & $A_{v v}$ & $1.8 \mathrm{~m}^{2}$ \\
\hline Aerodynamic coefficient & $c_{w}$ & 0.220 \\
\hline Rolling coefficient & $c_{r}$ & 0.008 \\
\hline Nominal speed & $v_{n o m}$ & $80 \mathrm{~km} / \mathrm{h}$ \\
\hline
\end{tabular}


TABLE II

MOTOR DESIGN SPECIFICATION

\begin{tabular}{|l|c|c|}
\hline Description & Symbol & Nominal value \\
\hline \hline Continuous output power & $P_{\text {nom }}$ & $3500 \mathrm{~W}$ \\
\hline Peak power $(10 \mathrm{~s})$ & $P_{\text {peak }}$ & $5 \cdot P_{\text {nom }}$ \\
\hline Speed at $80 \mathrm{~km} / \mathrm{h}$ & $n_{n}$ & $660 \mathrm{rpm}$ \\
\hline Continuous torque & $T_{n o m}$ & $55 \mathrm{Nm}$ \\
\hline Peak torque $(10 \mathrm{~s})$ & $T_{\text {peak }}$ & $5 \cdot T_{\text {nom }}$ \\
\hline Nominal torque/active weight & & $4.8 \mathrm{Nm} / \mathrm{kg}$ \\
\hline Peak torque/active weight & & $24 \mathrm{Nm} / \mathrm{kg}$ \\
\hline
\end{tabular}

is not sufficient for reliable operation, especially in case of peak loads. Consequently, the aim of this paper is to present the development of an in-wheel hub motor with maximum efficiency and minimum mass added to the vehicle. High efficiency should maximize the operation range and prevent thermal overloads. The considered machine should drive a virtual vehicle with specifications listed in Table I. If in a different vehicle the mass exceeds these specifications, an additional hub motor may be added to achieve the desired performance. Based on the specifications of Table I, the required continuous power was calculated to reach the maximum speed. The rolling resistance of the tires $F_{r}$, the aerodynamic drag $F_{d}$, and the force $F_{\text {rise }}$ required to overcome an assumed slope of an angle $\alpha=20^{\circ}$ resulted in the motor design specification given in Table II. The required power $P_{\text {nom }}$ was calculated according to

$$
\begin{aligned}
P_{r} & =F_{r} v_{\text {nom }}=c_{r} g m_{v v} v_{n o m}, \\
P_{d} & =F_{d} v_{n o m}=\frac{1}{2} c_{w} \rho A_{v v} v_{n o m}^{3}, \\
P_{\text {rise }} & =F_{r i s e} v_{\text {nom }}=m_{v v} g \sin (\alpha) v_{n o m}, \\
P_{\text {nom }} & =\frac{P_{r}+P_{d}+P_{\text {rise }}}{\eta}
\end{aligned}
$$

with an assumed drive train efficiency $\eta=92 \%$. The other parameters are the mass density of air $\rho=1.25 \mathrm{~kg} / \mathrm{m}^{3}$ and the constant of gravity $g=9.81 \mathrm{~m} / \mathrm{s}^{2}$. To reach comfortable acceleration but within tolerable temperature rise, the desired peak power was set to 5 times the continuous power for a period of $10 \mathrm{~s}$. This overload case has to be verified by CFD and drive cycle analysis, which is partially covered in Subsection III-D.

The comparison of torque to weight ratios is common practice [10], but without taking the cooling system into account, it may be misleading. Nevertheless, the commercially available CSIRO motor with standard magnet arrangement [5] stands out by $97.5 \%$ efficiency and $1.95 \mathrm{Nm} / \mathrm{kg}$ (active parts). By adding forced air cooling, the continuous torque to weight ratio of was increased to $4.7 \mathrm{Nm} / \mathrm{kg}$ with unchanged efficiency. The CSIRO system serves as a benchmark for the motor to be developed in this paper. The goal is to achieve the increased torque to weight ratio not only theoretically but practically proven by a prototype. The design and validation workflow is shown in Fig. 2.

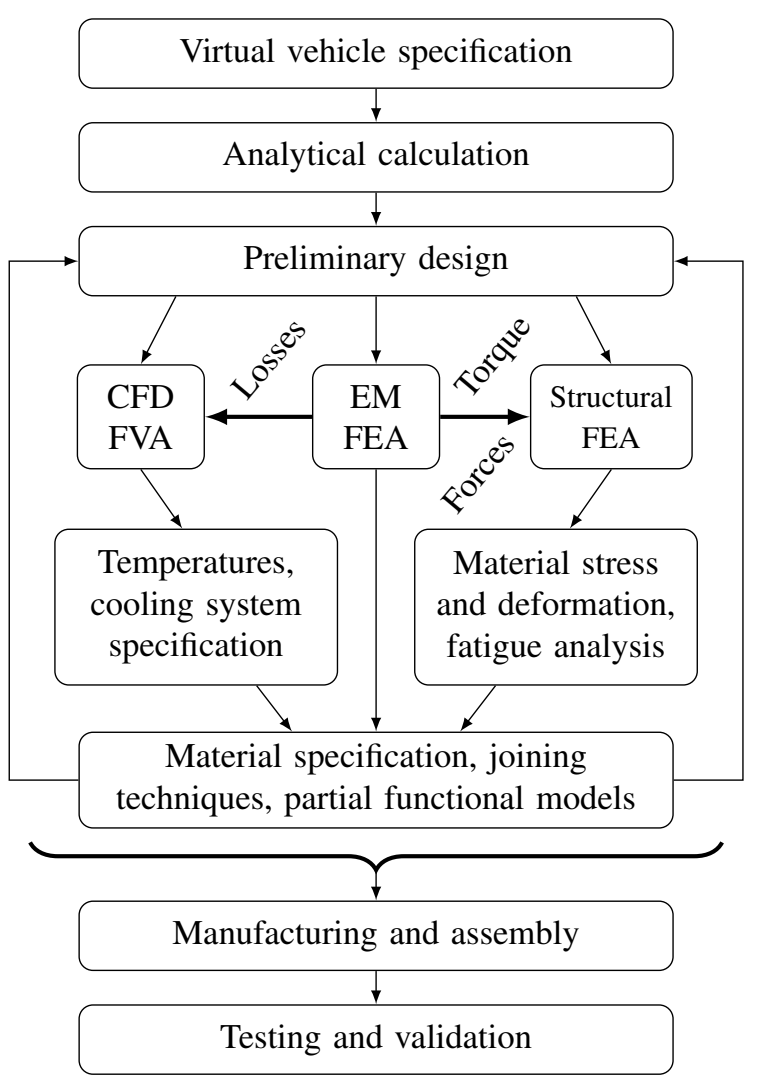

Fig. 2. Design and validation work flow

\section{METHODS}

\section{A. Analytical calculation and mechanical design}

Basic parameters like the feasible number of magnet segments per magnetic wavelength and the general size of the motor were calculated according to [11]. The peak magnetic flux density $\hat{B}$ for segmented Halbach arrays with the magnet height $h_{m}$ and the number of magnets $n_{m}$ per spatial period $\lambda$ is given by

$$
\hat{B}=B_{r}\left(1-\mathrm{e}^{\frac{-2 \pi h_{m}}{\lambda}}\right) \text { si }\left(\frac{\pi}{n_{m}}\right) .
$$

$B_{r}$ denotes the remanent magnetic flux density of the chosen magnet material. Under the assumption of sinusoidal current $I_{r m s}$ and magnetic flux $\phi$ derived by $\hat{B}$, the electromagnetic torque $T$ is

$$
T=\frac{m_{1}}{\sqrt{2}} p N \phi I_{r m s} .
$$

Here, $m_{1}$ is the number of phases, $p$ is the number of pole pairs, and $N$ is the number of turns per phase. The general design is shown in Fig. 3. The wheel hub is an important mechanical part for the motor design. The weight of the vehicle and the motor torque have to be transferred between the chassis and motor. Two symmetric CFRP half rims are mounted onto the hub with deep groove ball bearings and are 


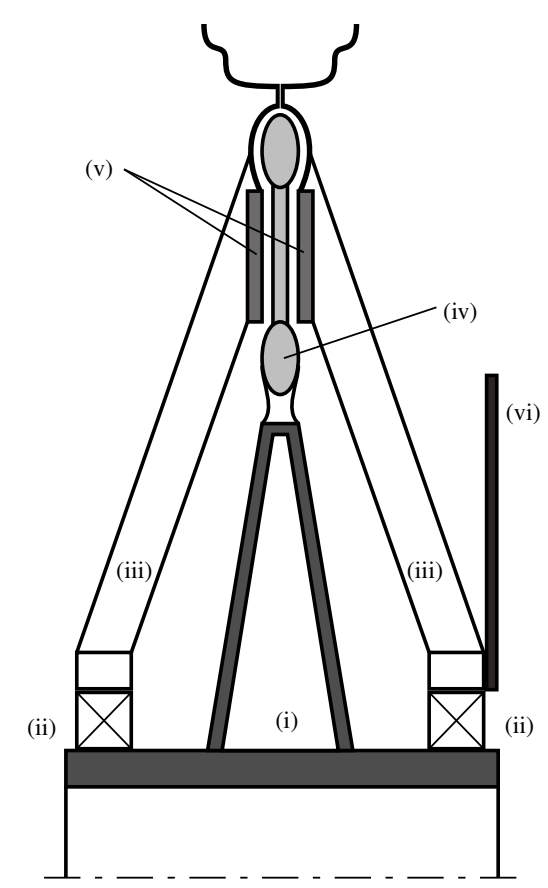

Fig. 3. Cross section of in-wheel hub motor: (i) light metal hub, (ii) bearings, (iii) two symmetric CFRP half rims, (iv) air cored winding with GRP connection to the hub, (v) two Halbach magnet array rings, (vi) brake disk

bolted together at their outer circumference (just inside the tyre). Two rim edges provide the support for a standard tire. The inner surface of each half rim is connected to the magnet array ring to provide the magnetic field which interacts with the winding. The air cored winding consists of Litz wires to limit eddy current losses and is encapsulated by casted resin containing filler. The inner winding head is connected to the spoked hub using multiple layers of GRP and membranes between the four hub spokes.

\section{B. Electromagnetic design and FEA}

As indicated in Fig. 2, 3D electromagnetic FEA is used for determining the input data for the CFD and the structural analyses. A detailed winding and magnet array section model with approximately 120000 second order tetrahedral elements was created and the geometry is shown in Fig. 4. The magnetostatic solver calculates the magnet attraction forces between the two CFRP rims, evolved torque, flux density distributions, and winding losses. A detailed design study of the magnet shapes and their effect on the evolved torque as well as the induced voltage characteristic are given in [12].

\section{Structural FEA}

Structural FEAs of the mayor parts have been carried out to analyse different load cases like acceleration during cornering. The considered loads are given in Table III. The half rims were modelled with quasi-isotropic CFRP laminat and combinations of the load cases like cornering with acceleration were applied. The result for the emergency brake load case result is shown in Fig. 5. The failure criterion according the theory of Puck was

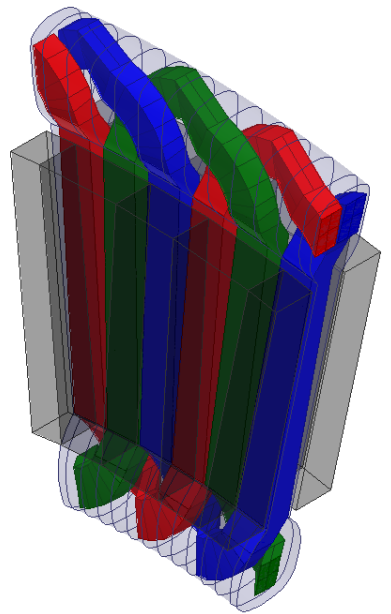

Fig. 4. 3D motor section for electromagnetic FEA

TABLE III

MECHANICAL LOAD CASES

\begin{tabular}{|l|c|c|}
\hline Description & Symbol & Nominal value \\
\hline \hline Vehicle weight $\left(m_{v v} \cdot \mathrm{g}\right)$ & $F_{v v m}$ & $2450 \mathrm{~N}$ \\
\hline Maximum torque & $T_{p e a k}$ & $275 \mathrm{Nm}$ \\
\hline Emergency mechanical braking torque & $T_{e m b}$ & $260 \mathrm{Nm}$ \\
\hline Magnet attraction force & $F_{m a g}$ & $12 \mathrm{kN}$ \\
\hline Cornering transverse force $\left(1.5 \cdot m_{v v} \cdot \mathrm{g}\right)$ & $F_{c t}$ & $3680 \mathrm{~N}$ \\
\hline Curb contact (angle $\left.30^{\circ}, 2.5 \cdot m_{v v} \cdot \mathrm{g}\right)$ & $F_{c c}$ & $6130 \mathrm{~N}$ \\
\hline Tire pressure & $p_{t i r e}$ & $5 \mathrm{bar}$ \\
\hline
\end{tabular}

used for the judgement of critical fibre and inter-fibre failure. Consequently, the maximum stress has to be transformed into the fibre direction and perpendicular to the fibre at the volume of interest. The number of CFRP layers were increased until criterion was fulfilled.

The primary purpose of the wheel hub is to provide the

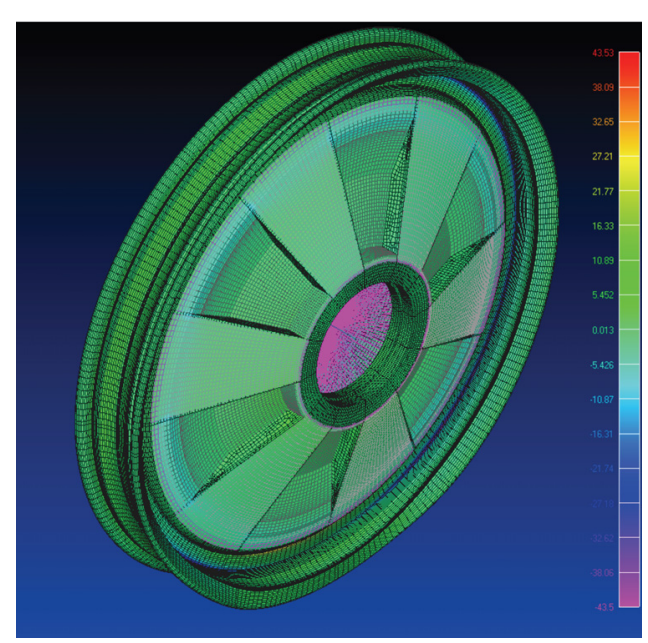

Fig. 5. CFRP structural FEA result, stress plot, scale: $-43.5-43.5 \mathrm{MPa}$ applied load: braking torque, vehicle mass, tire pressure and cornering transverse force 

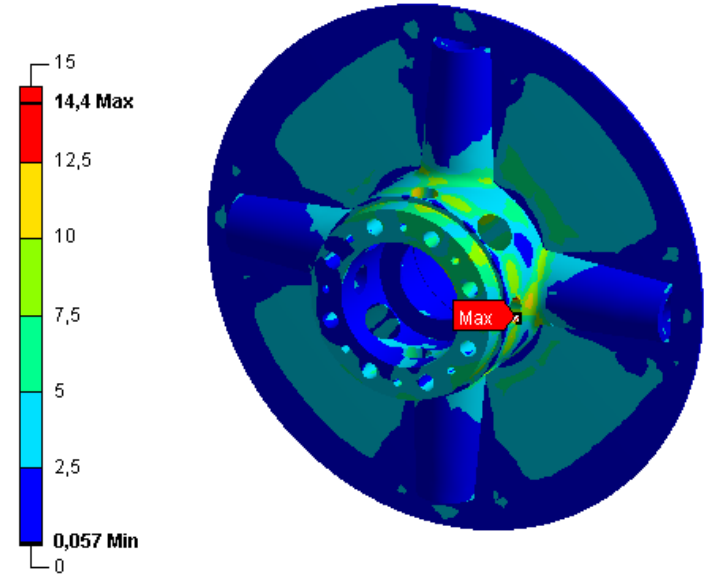

Fig. 6. Wheel hub structural FEA result, von Mises stress plot scale: 0 - $15 \mathrm{MPa}$, applied load: maximum torque and vehicle weight, interior view

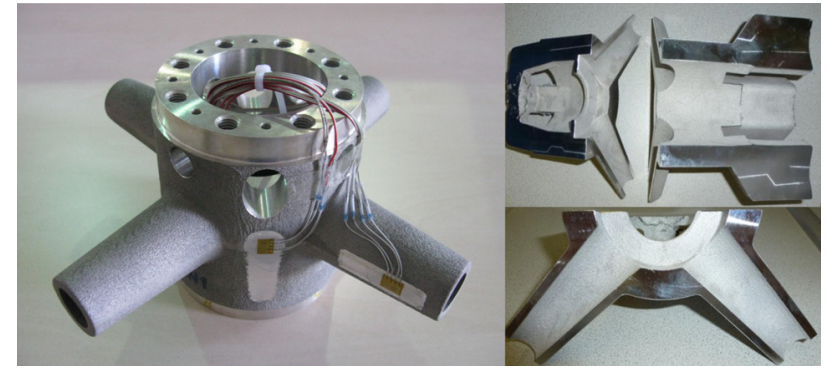

Fig. 7. Machined wheel hub equipped with strain gauge sensors and two half-cut views to prove the casting process

link between the motor and the chassis to transfer both the defined drive torque and the vehicle weight. In order to provide a stiff and reliable component, the magnesium alloy AZ91 (AlMg9Zn1) was selected for casting. This magnesium alloy is a well proven alloy system for casting and it features acceptable fatigue strengths at both low and high temperature. The manufacturing of the prototype hubs was done by sand casting. The design of the casting mould was supported by mould filling simulations in ProCAST to avoid erroneous solidification and shrinkage cavaties. Structural FEA of the hub and the middle GRP were carried out using approximately 120000 linear hexahedral elements and a linear-elastic material model for AZ91 and GRP. The vehicle weight and maximum torque load case resulted in a maximum vonMises stress of $14.4 \mathrm{MPa}$ (cf. Fig. 6). Consideration of the Wöhler curve for AZ91 material leads to a minimum of $10^{6}$ allowable load cycles for this case.

A preliminary series of wheel hubs was produced to prove the casting and manufacturing process. Fig. 7 shows a wheel hub equipped with strain gauge sensors and two half-cut views to prove the casting process. To verify the quality of the casted material, X-ray inspections and tensile specimen tests were carried out.

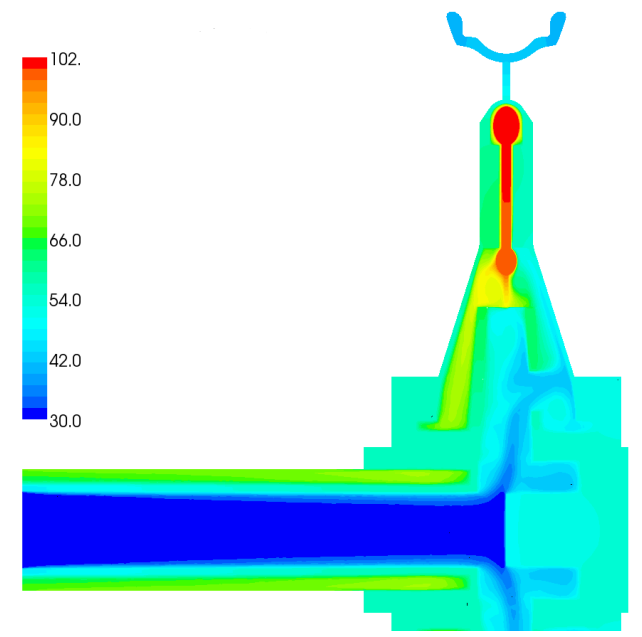

Fig. 8. CFD result, temperature distribution for winding losses averaged during a typical drive cycle, ambient temperature $30{ }^{\circ} \mathrm{C}$, inlet air flow rate $1.63 \mathrm{~g} / \mathrm{s}$

\section{CFD FVA}

The preliminary 3D geometry was simplified for CFD FVA and a mesh consisting of approximately 1.6 million polyhedral elements was generated. Losses of $200 \mathrm{~W}$ were assumed to occur on average during a typical drive cycle. These losses were modelled as heat sources terms equally distributed over the winding and the effectiveness of forced air cooling was studied. The air flow rate was set to $1.63 \mathrm{~g} / \mathrm{s}$ with an inlet temperature of $30^{\circ} \mathrm{C}$. The resultant temperature distribution is shown in Fig. 8. The coolant enters the motor from the left side and is directed to the right via the centred duct of the hub. The air is radially distributed and passes the hot winding and the magnet through the air gap, first through the exterior air gap (right-hand side in Fig. 8), then through the interior air gap (left-hand side in Fig. 8). Finally, the warm air leaves the motor through vents connected to outside ring inside the hub. Under the defined operation condition, the maximum temperature for the winding is $101{ }^{\circ} \mathrm{C}$ and $63{ }^{\circ} \mathrm{C}$ for the magnets. Streamlines shown in Fig. 9 visualize the temperature conditions along the fluid flow. This analysis helped to avoid unnecessary turbulences and hot spots. Fig. 9 shows the flow path of the air. It first flows through the centered duct of the hub, passes the exterior and the interior air gap and leaves the wheel through eight vents (cf. Fig.6) to the outlet duct.

\section{REALIZATION}

After the design freeze, the concept will result in manufacturing several prototypes. Final materials selection will be made based on the above FEAs. Considering all design aspects, data sheets usually provide only limited information. For instance, the minimum bending radius for custom-made Litz wire or the thermal characteristics of sintered rare-earth magnets below room temperature are usually not available. Therefore, these informations were gathered by experiments shown in Fig. 10. Different winding topologies were investigated to get realistic winding head dimensions. Different 


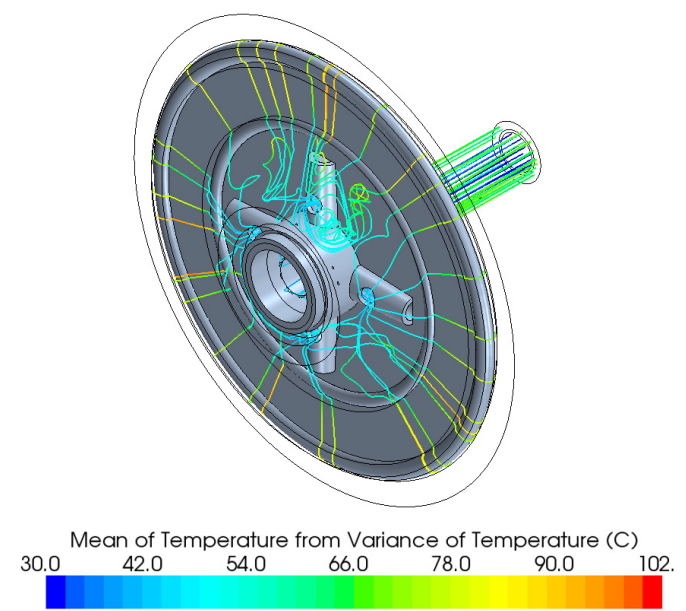

Fig. 9. CFD result, temperature distribution along the streamlines, averaged drive cycle winding losses, ambient temperature $30^{\circ} \mathrm{C}$, inlet air velocity $2 \mathrm{~m} / \mathrm{s}$, exterior view

(i)

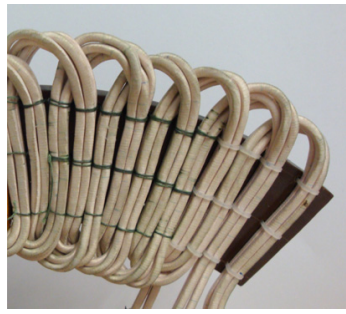

(ii)

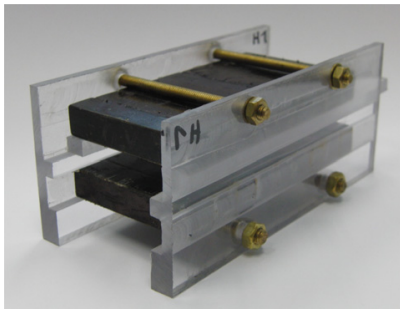

(iii)

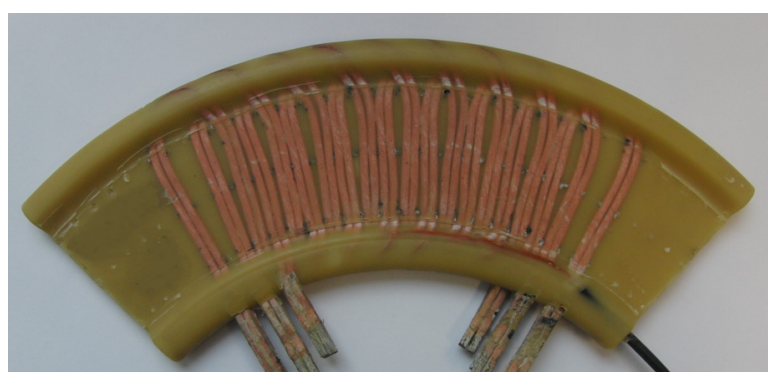

Fig. 10. Functional models, (i) Air gap winding, (ii) Double sided Halbach magnet array ( 9 pieces 10x10x45 mm each), (iii) Moulded air gap winding

resins were used for manufacturing quarter models of the molded air gap winding. Fig. 10 (iii) shows a design with polyurethane resin. Significant magnetic forces occur during the assembly of the Halbach arrays. Small scale linear arrays were manufactured in order to determine different assembly strategies. An example is shown in Fig. 10 (ii). Degrading effects ranging from $-20{ }^{\circ} \mathrm{C}$ to the maximum operating temperature were measured and evaluated for different magnet material grades. Electromagnetic FEA and measurements showed an augmented temperature degrading effect within segmented Halbach arrays [13].

\section{CONCLUSION}

A concept for an ironless in-wheel hub motor and the work flow towards manufacturing and assembly were presented in this paper. The virtual vehicle specification and analytical design variations lead to a preliminary design and the creation of 3D models. 3D EM FEAs demonstrated the functionality and provided source data for CFD FVA illustrating the temperature distribution and the heat flows of the cooling system. Structural FEAs yielded the performance and fatigue behavior of the used components. Moreover, several concepts for manufacturing the components were devised and experimentally tested. These concepts include joining and encapsulation techniques, winding arrangement, and magnet assembly.

\section{ACKNOWLEDGMENT}

The authors gratefully acknowledge the support of the Austrian Research Promotion Agency (Oesterreichische Forschungsfoerderungsgesellschaft $\mathrm{mbH}$, Klima- und Energiefonds, Neue Energien 2020) for the research project 829727 HeAL - High efficient ironless drive for lightweight vehicles and the project partner DFM technologies.

\section{REFERENCES}

[1] M. Anderson and D. Harty, "Unsprung mass with in-wheel motors-myth and realities," in 10th International Symposium on Advanced Vehicle Control, (AVEC'10), Aug. 2010, pp. 261-266.

[2] D. van Schalkwyk and M. Kamper, "Effect of hub motor mass on stability and comfort of electric vehicles," in IEEE Vehicle Power and Propulsion Conference, (VPPC'06), Sept. 2006, pp. 1-6.

[3] Z. Zhang, F. Profumo, and A. Tonconi, "Axial flux interior PM synchronous motors for electric vehicle drives," Symposium on Power Electronics Electrical Drives Automation and Advanced Electric Motors, (SPEEDAM'94), pp. 323-328, Jun. 1994.

[4] F. Profumo, F. Eastham, A. Tenconi, and G. Gianolio, "’'Plastic" electric motors: a viable solution for axial flux machines," in Proceedings of the 2002 IEEE International Symposium on Industrial Electronics, (ISIE'02), vol. 1, 2002, pp. 1-10.

[5] H. Lovatt, V. Ramsden, and B. Mecrow, "Design of an in-wheel motor for a solar-powered electric vehicle," IEE Proceedings Electric Power Applications, vol. 145, no. 5, pp. 402-408, Sept. 1998.

[6] R. Al Zaher, S. de Groot, H. Polinder, and P. Wieringa, "Comparison of an axial flux and a radial flux permanent magnet motor for solar race cars," in XIX International Conference on Electrical Machines, (ICEM'2010), Sept. 2010, pp. 1-6.

[7] J. Mallinson, "One-sided fluxes - A magnetic curiosity?" IEEE Transactions on Magnetics, vol. 9, no. 4, pp. 678-682, Dec. 1973.

[8] K. Halbach, "Design of permanent multipole magnets with oriented rare earth cobalt material," Nuclear Instruments and Methods, vol. 169, no. 1, pp. $1-10,1980$.

[9] J. Ofori-Tenkorrang and J. Lang, "A comparative analysis of torque production in Halbach and conventional surface-mounted permanentmagnet synchronous motors," in Conference Record of the 1995 IEEE 30th IAS Annual Meeting Industry Applications Conference, (IAS'95), vol. 1, Oct. 1995, pp. 657-663.

[10] H. Zelaya De La Parra, F. Magnussen, and S. Bosga, "Challenges for electric machines and power electronics in automotive applications," in International Conference on Ecological Vehicles and Renewable Energies, (EVER'09), Nov. 2009, pp. 1-9.

[11] J. F. Gieras, R.-J. Wang, and M. J. Kamper, Axial Flux Permanent Magnet Brushless Machines, 1st ed. Dordrecht, The Neatherlands: Kluwer Academic Publishers, 2004.

[12] O. Winter, C. Kral, and E. Schmidt, "Design study of magnet shapes for axial Halbach arrays using 3D finite element analyses," Accepted for presentation at XX International Conference on Electrical Machines, (ICEM'12), p. 6, Sept. 2012.

[13] O. Winter, C. Kral, and E. Schmidt, "Augmented temperature degrading effect of rare earth magnets arranged in segmented Halbach arrays," Accepted for presentation at IEEE International Magnetics Conference, (INTERMAG'12), p. 4, May 2012. 